\title{
Intercultural communication: concept, essence and theories of intercultural communication
}

\author{
Jumaev Ulugbek Sattorovich ${ }^{1}$ \\ ${ }^{1}$ Candidate of psychological sciences, docent. Bukhara state university, psychology department
}

\begin{abstract}
The author conducts globalization impact conceptual analysis on the national culture and cultural identity formation and development in contemporary societies. The main focus is driven on such issues, as the globalization phenomenon, the extent to which national cultures are exerted influence by globalization, as well as threats and opportunities produced by globalization that reflect on cultures.
\end{abstract}

Key words: conceptual analysis, globalization phenomenon, intercultural adaptation.

\section{INTRODUCTION}

Currently, intercultural adaptation in international business is one of the urgent problems in the intercultural communication field, which study is important for specific practical recommendations development. Many literary sources present researchers different opinions and positions on this issue. The main approach when considering this issue is authors desire to identify universals, i.e. those characteristics that are similar for all crops. These universals represent universal, general humanitarian basic values and moral and ethical norms set. These characteristics, initially forming cultures community, can be considered as mutual understanding and interaction foundation between representatives of different nations, the basis for establishing business contacts. At the same time, along with the universals that bring the nations closer together, there are a number of characteristics specific to each individual culture. Such characteristics, which are called structural features and in their structured community form one particular culture's specific profile, include, in particular, their labor activities organization peculiarities by different peoples. The work relevance is associated with a significant communication production sphere complication, especially in recent years. The economic, managerial, commercial, and legal areas of professional activity have become widespread and developed, which makes it necessary for specialists to master the professional culture skills as an important component of professional intercultural communication.

\section{MAIN PART}

Intercultural communication is communication between different cultures representatives (personal contacts between people, less often - indirect communication forms (such as writing and mass communication). The intercultural communication features are studied at an interdisciplinary level and within cultural studies, psychology, linguistics, ethnology, anthropology, sociology sciences framework, each of which uses its own approaches to their study.

The "intercultural communication" concept was introduced in 1950s by the American anthropologist Edward T. Hall as program part he developed for the US State Department to adapt American diplomats and businessmen in other countries.

Initially, to describe intercultural communication, a more accurate classical understanding of culture was used as a more or less conscious and unconscious rules stable system, norms, values, structures - national or ethnic culture.

Currently, a dynamic understanding of culture as a life way and a behavior system, norms, any social group values increasingly dominates. The dynamic culture concept does not imply a cultural system strict stability; it can change and be modified depending on the social situation.

As a scientific discipline, intercultural communication is at the formation stage and is distinguished by two characteristic features: an applied nature (the goal is to facilitate communication between different cultures representatives, reduce the potential for conflict) and interdisciplinarity.

Any group of people with their own culture can be characterized by the following categories:

* oneself and space awareness. Different cultures have their own "comfort zone" idea. Some cultures are quite strictly structured and formal, while others are flexible and informal. Some cultures are closed, and the place of each individual in them is clearly fixed, some are open and changeable. Each culture evaluates personality in its own way;

* $\quad$ communication (conversation) and language. The communication system (both verbal and non-verbal) distinguishes one culture from another. In addition to the many languages that exist in the world, some nations have several state ones, while others have dialects, slangs and other variants within one language. Common human gestures are also interpreted differently in different cultures.

* $\quad$ clothing and appearance. These include outerwear and ornamentation (or lack thereof) and body ornaments that distinguish one culture from another. In some cultures, tribal members paint their faces before battle to intimidate the enemy, while in others, women use makeup to showcase their beauty.

* food and conduct rules at the table. Different cultures have their own way of choosing food, preparing, serving and eating it. The food consumption manner also differs in different cultures: someone eats 
with his hands, someone with chopsticks, and someone uses a complex set of various forks and knives, tweezers and spoons. But even when using the same tools (such as a fork and a knife), people from different cultures handle them differently.

* time and its perception. The attitude to time is different in different cultures: some are punctual, others are free with time. In some countries, status and age determine when to arrive at a business meeting, with subordinates arriving first and the boss last.

* relationship. Each culture reinforces certain human relationships depending on age, gender, status, kinship degree, as well as wealth, wisdom and power. The family, the most common unit in many societies, ranges from small to large. The relationship between people is also determined by culture: in some countries elders are honored, in others they are ignored; in some countries, women must cover their faces and show respect, obedience, in others they are equal with men.

* norms and values. Both the society needs and the priority behavior forms are also determined by culture. In underdeveloped countries, the basic society needs include food and shelter. In developed countries, money, material wealth, titles and positions, as well as law and order acquire value. Depending on the values system existing in the country, behavior norms of society members are established, ranging from permissiveness to strict obedience for children. Cultural norms determine the conduct ethics at work, form traditions and rituals, define the private life boundaries, establish good manners and exemplary behavior rules;

* religious beliefs and imagine system. The most difficult problem is to isolate the basic ideas of a certain culture and factors that influence the representatives attitude of this culture to themselves, to others, to events in their environment. Religious traditions in different cultures, knowingly or unknowingly, influence our attitude towards life. Religion and beliefs system prevalent in society, to a certain extent, depend on the society development level: tribes and societies at a primitive development level are very superstitious, which is confirmed by the shamanism rituals; some religions are strongly associated with the agricultural development stage, while at the advanced technological stage, more and more people instead of religion believe in science;

* mental activities and teaching methods. People in different cultures think and learn differently. In every society, culture determines the rewards and punishments for the assimilation or nonassimilation of this or that information in a certain way. Some cultures value abstract thinking and contemplation; others prefer rote memorization and memorization. Mental activity is present in all cultures but manifests itself in different ways;

* labor organization and attitude to work. Everything related to work: attitudes towards work, basic work activities types, labor division, work methods and principles, also distinguish one culture from another. Work is defined as stress or effort to produce or accomplish something.

Time and attitude perception towards it is one of the most common criteria for comparing cultures. For example, E. Hall distinguishes between monochronic and polychronous cultures. In monochronic cultures (the United States of America and the countries of Northern Europe), at each certain time period, people are busy with one thing, they strictly follow plans, schedules and agreements to avoid wasting time. Punctuality is important to them, and being late is considered a serious social norms violation. In polychronous cultures (countries of Southern Europe, Latin America, the Middle East), people do several things at the same time, and relationships between people are more important to them than plans and schedules.

The same criterion (relation to time) is used by R.D. Lewis in his cultures comparison. Lewis divides cultures into three types: monoactive (or linearly organized), polyactive, and reactive. Monoactive peoples, such as Swedes, Swiss, Danes and Germans, do one thing in a given time period, fully focus on it and carry out according to a predetermined schedule. They believe that with such a labor organization, they act more effectively and fruitfully.

Polyactive cultures representatives (Hispanics and Southern Europeans) are easily rebuilt and can do several things at the same time, but they do not like to interrupt the conversation in mid-sentence. For them, completing interpersonal interactions is the best way to invest their time. The reactive cultures that are Asian countries characteristic organize activities not according to a strict and unchanging plan, but depending on the changing context, responding to these changes.

The American anthropologist E. Hall compares cultures depending on their relationship to the context, by which he understands the information surrounding and accompanying the event, that is, what is woven into the significance of what is happening. Most information in highly contextual communication is already known to a person and only a small part of it is presented in words (encoded, externally expressed communication way). In low-context communication, most information is transmitted by a symbolic (sound-letter) code.

For representatives of highly contextual cultures, much has been said and determined by the nonlinguistic context: hierarchy, status, office appearance, its location and location.

E. Hall provides a two extreme degrees comparison of high and low contextual cultures.

Highly contextual cultures (East) are distinguished by:

- unexpressed, speech hidden manner, meaningful and numerous pauses;

- serious importance is attached to non-verbal communication and the ability to "say with eyes";

- information redundancy is unnecessary;

- conflict is destructive (these cultures representatives do not like to directly sort things out and discuss problems); 
dissatisfaction open expression is not acceptable under any circumstances.

Low-context cultures (West) are distinguished by:

- direct and expressive speech manner, silence distrust;

- non-verbal communication is less significant;

- everything should be expressed in words and everything should be given a clear assessment, innuendo is associated with insufficient information of the speaker;

- the conflict is constructive, as the identified problems and difficulties discussion helps to make the right decision;

- in some cases, an open dissatisfaction expression is possible.

In low-context cultures, interpersonal relationships are often temporary and superficial. People easily enter into friendships and just as easily break them off. In highly contextual countries, interpersonal relationships develop more slowly and more difficult, but differ in strength and duration.

Highly contextual cultures are most often collectivist. At the same time, great importance is attached to personal relationships and oral agreements. Low-context cultures are distinguished by individualism, their representatives value personal relationships less, and more written agreements.

According to Hofstede's theory (four parameters of cultural comparison), in order to create conditions for cooperation, international leaders must study not only the customs, conduct and business protocol rules of their partners - other cultures representatives, but also understand their national character, management traditions and way of thinking. Hofstede's theory identifies the main parameters for determining the culture national character.

Individualism - collectivism. Individualism is a society with a free/non-rigid social structure, in which everyone takes care of himself and his family. Collectivism is a society with a rigid/strict social structure, a clear division into social groups (kinship, clan, organizational, etc.), within which each individual is guaranteed the care and attention of the rest in exchange for loyalty to the group.

In individualistic cultures, people do not show emotional dependence on organizations and institutions. Everyone's right to personal property, private opinion, and their point of view is appreciated. The individual initiatives importance and individual success is emphasized, the ability to independently make decisions is encouraged.

In collectivist cultures, which include most Latin American and Middle Eastern countries, people perceive the world and form their attitude towards it through the group prism; loyalty to the organization, friends, family is paramount. Power distance is society readiness degree to accept inequality in the power distribution in relationships, in institutions, organizations. This is reflected in the society attitude towards those who are endowed with power and those who are deprived it. In an organization, this parameter is expressed in the power and status distribution at various organizational levels. On the power distance scale, Germany, Great Britain, Austria, Finland, Denmark, Norway are low, France, Belgium and many Latin American and Middle Eastern countries are high.

Cultures representatives with a high power distance believe that people are born unequal, everyone has their own place in life, due to the complex society hierarchical structure, and the distance between different social strata is significant. The organizational structures of such cultures are characterized by centralized power, large control and inspection personnel numbers, and a strict value system that determines a given job value. There is a strong belief that those in power are fundamentally different from the rank and an organization file, so any power exercise is considered the norm.

Uncertainty fear is the threat degree faced by society in implicit, ambiguous situations. Cultures representatives with a high degree of uncertainty fear try to avoid ambiguous situations by securing themselves with many formal rules, deviations rejection from the norm in thoughts or behavior, belief in absolute truth. They have a strong need for written instructions, rules and laws that give certainty to life. People belonging to these cultures prefer clear goals, detailed assignments, rigid schedules and schedules.

Cultures with masculine and feminine principles. G. Hofstede emphasizes that this parameter of his cultures classification has nothing to do with men or women, but only with the certain (more typical for men or women) traits predominance in the national character.

G. Hofstede calls male culture in which vanity, striving for success, achievements recognition and concern for high prosperity are valued, and female is one in which the importance of interpersonal relations, cooperation, the desire for understanding prevails and care for the people around is shown.

All emerging intercultural communication problems sociolinguists, in particular J. Chick, reduced to the following three main reasons:

- the differentiating nature of the cultural values set in different cultures - each separately taken cultural values system is inherent in a particular culture;

- fuzzy configuration (boundaries blurring) of social relations when one and the same person is different social groups member;

- the dominant ideologies presence in cultural groups.

\section{CONCLUSION}

Thus, going beyond the culture boundaries, it is not enough for a person to overcome the language barrier to ensure the communication effectiveness with representatives of other cultures. He also needs to 
overcome the cultures barrier, i.e. to plunge and try to get used to another world, somewhat different from the usual. To effectively enter another culture, it is necessary to study the behavior and communication norms of its representatives, due to which it will be possible to merge with this culture together and not feel like an outcast in a foreign society.

\section{REFERENCES}

1. Kuzhevskaya, E. B. Intercultural business communication and problems of forming the image of a modern Russian entrepreneur: philosophical and cultural aspect: author's abstract. dis ... kand. filosofovsk. nauk: 24.00.01 / E. B. Kuzhevskaya-Moscow, 2005. - 155 p.

2. Baulina, V. S. Influence of national character on the process of international negotiations. Moscow, 2006

3. Grushevitskaya, T. G., Popkov, V. D., Sadokhin, A. P. fundamentals of intercultural communication, Moscow, 2005, 79 p.

4. Kibanov A. Ya., Zakharov D. K., Konovalova V. G. Ethics of business relations: Textbook / ed. by A. ya. Kibanov. - M.: INFRA-M, 2007. - 368 p. - (Higher education).

5. Emysheva E. Some features of conducting negotiations with representatives of different countries, Moscow, 2005.

6. kabushkin N. L. Fundamentals of management: Textbook.manual-7th ed., stereotype. - Mn.: New knowledge, 2005. - 336 p.

7. Kuzin F. A. Culture of business communication. - Moscow: OS-89, 2004. - 320 p.

8. Sadokhin, A. P. Competence and competence approach in the dialogue of cultures. Journal of sociology and social anthropology. 2008. Vol. XI. no. 2. P. 8092.

9. Gesteland Richard R. Cross-cultural behavior in business. Marketing research, negotiation, management in different cultures. - Dnepropetrovsk: LLC "Balance-Club", 2003. - 272 p.

10. Chekhov M. I. Psychology of business communication: textbook.- M.: New knowledge, 2006. 